\title{
Understanding the early host immune response against Mycobacterium tuberculosis
}

\author{
BABBAN JEE
}

Department of Health Research, Ministry of Health and Family Welfare, Government of India, New Delhi, India

\begin{abstract}
Generation of immune response is a crucial activity of host defense against any microbial attack. When facultative organism Mycobacterium tuberculosis (MTB) invades its host, various pathways are activated in the host to mount immune responses against invading pathogen for nullifying its actions. During this host-pathogen interaction, interplay of complex network of cytokines and chemokines, initiation of phagocytosis, and formation of granuloma play an important role in containing MTB infections at host side. Simultaneously, MTB also evolves a plethora of specialized mechanisms to evade the host's killing cascades on other side, and during this bilateral cross-talk, many mycobacterial products play crucial role in survival of MTB inside the host. Hence, a better understanding of these phenomena is necessary not only for getting clear picture of pathogenesis of MTB, but also for developing effective, preventive, and therapeutic modalities against the pathogen. With some suggestions on future work, an insight into diversity of immune response of host against MTB was provided in the present review.
\end{abstract}

Key words: Mycobacterium tuberculosis, host, immune response, immune evasion.

(Centr Eur J Immunol 2020; 45 (1): 99-103)

\section{Introduction}

In the evolutionary niche of microbial world, tubercle bacilli (originally named Bacterium tuberculosis) further renamed as Mycobacterium tuberculosis (MTB), a landmark discovery of noted microbiologist Heinrich Hermann Robert Koch stands out with its impact on actual history of mankind. Having the close intimacy with genera Corynebacterium, Rhodococcus, and Nocardia, Mycobacterium tuberculosis is a genuine member of "single species containing" genus "Mycobacterium", which has been placed in the Mycobacteriaceae family [1]. Characteristically, it is an aerobic, slow growing, non-motile, non-spore forming, and acid-fast bacilli (AFB) with facultative nature.

Mycobacterium tuberculosis is an etiological agent of tuberculosis (TB), a disease that ranks above AIDS in causing worldwide mortality and morbidity. In 2016, tuberculosis claimed 1.3 million lives in HIV-negative people, in addition to 374,000 lives in HIV-positive people. About 6.3 million people got new MTB infections across the globe. One third of population of the world is believed to be latently infected with MTB, of which about 5-15\% will develop active disease with favorable conditions [2]. Although, best therapeutic modalities are available, the tuberculosis remains a major challenge around the world. The emergence of various drug-resistant forms of MTB, poor adherence to treatment protocol, poor hygienic and nutritional status, smoking, and alcohol consumption are the possible factors responsible for this situation $[3,4]$. The administration of certain drugs and microbiological product has also been found as iatrogenic cause of TB [5-7].

Since effective control of this disease is of prime importance, there is a necessity to have better understanding of the complex biology of MTB-host interactions, particularly of host immune response. Considering this requirement, in the present review, various aspects of host immune response against MTB were discussed in great details.

\section{The route of entry of Mycobacterium tuberculosis}

The mechanism of pathogenesis of MTB is very complex and partially understood. The initiation of pathogenesis possibly occurs with the entry of MTB into the host body through three possible routes such as 1) inhalation of contagious droplet nuclei harboring MTB into the respiratory tract; 2) gastrointestinal; 3) cutaneous [8]. Of these, respiratory tract is the widely acclaimed gateway for the introduction of MTB inside the host and subsequent progression of the disease. The number of individuals harboring MTB in general population varies because the source of infection and degree of exposure are mainly unknown. However, it is assumed that about $90 \%$ individuals of in-

Correspondence: Dr. Babban Jee, Department of Health Research, Ministry of Health and Family Welfare, Government of India, 110001 New Delhi, India, e-mail: babban.jee@gov.in Submitted: 11.01.2018, Accepted: 5.03.2018 
fected population have MTB infections and survive lifetime due to their strong immunity [9].

\section{Cross-talk between Mycobacterium tuberculosis and macrophage: inside story}

After inhaling by host, only a small fraction (10\%) of MTB reaches the bronchioles and alveoli of respiratory tract [10], where they interacts with variety of host cell receptors including Fc receptors (FcR), complement receptors (CR), surfactant protein receptors, macrophage mannose receptor (MMR), dectin-1, dectin-2, DC-SIGN, Nods, and Toll-like receptors (TLRs), particularly TLR2/4 of macrophages [11]. Once MTB is engulfed by macrophages, the process of phagocytosis is initiated to kill the tubercle bacilli residing in phagosomes. This includes the fusion of MTB-containing phagosomes with lysosomes that resulted in development of phagolysosomes [12]. However, on other side, for evading the host immune responses particularly killing mechanisms of lysosome, MTB tries to stop the maturation of MTB-containing phagosomes into phagolysosomes [13], and maintain a conducive environment for its survival in phagosome. In this process, exclusion of vacuolar $\mathrm{H}^{+}$-ATPases from MTB-containing phagosomes plays a vital role in assisting the pathogen to survive within the acidic environment of phagosomes [14]. Apart from this, tethering [15] and fusion machinery involved in trafficking of intracellular vesicles [16], including SNARE proteins (soluble N-ethylmaleimide-sensitive factor-attachment protein receptor) and small GTP-binding proteins of the Rab family such as Rab5 and Rab7 [17], are crucial for the biogenesis of phagolysosome [18]. Surprisingly, a $43 \mathrm{kD}$ tryptophan-aspartic acid repeat actin-binding protein of the host, i.e. TACO (tryptophan aspartate rich coat protein, also known as coronin-1) takes part in the intracellular survival of MTB in phagosomes [19].

\section{Granuloma formation: cardinal sign of host immune response}

The formation of granuloma is thought to be a cardinal feature of early host immune response against MTB. Therefore, a great deal of effort has been made over the last years across the world to understand the mechanism of granuloma formation and its need in defense against MTB. A series of studies suggests that by forming the granuloma, host attempts to contain MTB infection in macrophage and limits its further dissemination [20]. However, the formation of granuloma itself is a very complex mechanism, and till date not fully understood. Although, genesis of granuloma is assumed to be due to active involvement of both innate and acquired immune responses including variety of immune cells, cytokines/chemokines, cell-adhesion molecules (CAMs), and various signaling cascades [21-24]. Not only the host immune response, bacterial component like trehalose 6,6' - dimycolate (TDM) (cord factor) is also required for initiating the formation of granuloma [25].

Further, for elucidating the formation of granuloma and their importance in the pathogenesis of MTB, several hypotheses have been proposed. A hypothesis postulated by Dannenberg, which was based on findings of their work on rabbit model suggested that macrophages containing MTB send intracellular signals to neighboring immune cells for their deployment at the site of infection, thus, resulting in organization of cellular structure around infectious macrophages, which is known as granuloma [26, 27]. Another hypothesis suggested that just after MTB infection, neutrophils migrate first towards the site of infection followed by aggregation of monocytes, which take 2 to 3 days in differentiating of macrophages, and a well-structured granuloma is developed within 5 to 7 day of infection [28].

Studies were also carried out to provide insight into formation of granuloma in human cases. The classical type of human granuloma is made up of a central necrotic zone and an outer layer of leukocytes. The central necrotic area, which serves as source of nutrition for intracellular MTB is further surrounded by foamy macrophages, epithelioid cells, and Langhans giant cells (which are generated by epithelioid cells fusion), while the outer thick leukocytic wall preventing the dissemination of MTB is composed of a mixture of immune cells including $\mathrm{CD}^{+}$and $\mathrm{CD}^{+} \mathrm{T}$ cells [29]. When we compare the architecture of human and mice granuloma, we can find that the human granuloma structurally differs from mice granuloma, but the cells involved in its formation are almost similar in both the cases. Moreover, the mice granuloma, which lacks Langerhan's giant cells is a collection of loosely gathered activated and epithelioid macrophages as well as other immune cells including lymphocytes. Despite these architectural differences in human and mice granuloma, the function of granuloma is almost similar in both the cases [30, 31].

In the development of granuloma, the role of lymphocytes was found to be step guiding. Experimental evidences suggest that initiation of formation of granuloma primarily needs activation of T lymphocytes [32]. Once MTB is engulfed by dendritic cells in the lung [33], antigen processing is taken place. Just after, carrier dendritic cells are migrated to the draining mediastinal lymph nodes, where they interact with T lymphocytes. After activation by dendritic cells, $\mathrm{T}$ lymphocytes mediate protective immune response against MTB [34, 35]. Contrary to these observations, a study on MTB-infected mice suggested that for mediating the protective immune response against chronic infection of MTB, the presence of granuloma is necessary in addition to T lymphocytes [36]. The upregulation of members of cell adhesion molecules (CAMs) family on both leucocytes and endothelial cells further mediates the deployment of mononuclear phagocytes and activated $\mathrm{T}$ lymphocytes to the site of infection, leading to extravasation of these cells into the lung [20]. When we look back at the background of granuloma 
Table 1. Mediators of granuloma formation/maintenance

\begin{tabular}{|c|c|c|}
\hline Mediators & Produced by & Major role \\
\hline \multicolumn{3}{|l|}{ Cytokines } \\
\hline IFN- $\gamma$ & CD4+ and CD8+ T cells, NK cells & Macrophage activation \\
\hline TNF- $\alpha$ & CD4+ T cells, macrophages & $\begin{array}{l}\text { Macrophage activation, chemokine induction, granuloma } \\
\text { maintenance }\end{array}$ \\
\hline IL-1 & Macrophages, dendritic cells, monocytes & $\begin{array}{l}\text { Regulation of interferon (IFN) functions, recruitment of } \\
\text { phagocytic cells }\end{array}$ \\
\hline IL-6 & Monocytes, fibroblasts, T cells, B cells & Granuloma maintenance \\
\hline Il-10 & $\begin{array}{l}\text { Th2 cells, Th1, and Th17 cells, macrophages, dendritic cells, } \\
\text { myeloid derived suppressor cells, B cells, neutrophils, Treg cells }\end{array}$ & Macrophage deactivation \\
\hline IL-12 & Dendritic cells, macrophages, B cells & $\begin{array}{l}\text { Early } \mathrm{T} \text { cell activation and polarization, } \mathrm{T} \text { cells recruitment } \\
\text { in developing granuloma }\end{array}$ \\
\hline IL-13 & $\begin{array}{l}\text { Th2 cells, CD8+ T cells, NK cells, granulocytes (e.g. mast } \\
\text { cells, eosinophils, basophils) }\end{array}$ & Necrotic granuloma formation \\
\hline IL-17 & $\mathrm{CD}+\mathrm{T}$ cells $(\mathrm{Th} 17), \gamma \delta \mathrm{T}$ cells & $\begin{array}{l}\text { Induction of chemokines CXCL9-11, mediating } \\
\text { recruitment of T cells in granuloma, neutrophil } \\
\text { recruitment, macrophage activation }\end{array}$ \\
\hline IL-18 & Macrophages & $\begin{array}{l}\text { Neutrophil/monocyte accumulation, induction of IFN- } \gamma \text { by } \\
\text { T cells }\end{array}$ \\
\hline IL-23 & Dendritic cells, macrophages & Required for IL-17 and IL-22 production \\
\hline IL-27 & Macrophages, dendritic cells & Limiting migration of $\mathrm{T}$ cells towards site of infection \\
\hline TGF- $\beta 1$ & Lymphocytes, macrophages, monocytes, dendritic cells & $\begin{array}{l}\text { Formation of fibrous capsule around granuloma, } \\
\text { liquefactive necrosis, impairment of } \mathrm{T} \text { cells functions }\end{array}$ \\
\hline \multicolumn{3}{|l|}{ Chemokines } \\
\hline CXCL8 & $\begin{array}{c}\text { Alveolar macrophage, monocytes, alveolar epithelial cells, } \\
\text { bronchial epithelial cells }\end{array}$ & Recruitment of neutrophil, T lymphocytes, and basophils \\
\hline CCL2 & $\begin{array}{c}\text { Monocytes, alveolar macrophages, alveolar epithelial cells, } \\
\text { bronchial epithelial cells }\end{array}$ & $\begin{array}{l}\text { Recruitment of macrophages/monocytes, } \mathrm{T} \text { cells, and other } \\
\text { immune cells, polarization of näive } \mathrm{T} \text { cells to } \mathrm{Th} 2 \text { cells }\end{array}$ \\
\hline CCL3/4/5 & $\begin{array}{l}\text { Alveolar macrophages, dendritic cells, bronchial epithelial } \\
\text { cells }\end{array}$ & $\begin{array}{l}\text { Recruitment of macrophages/monocytes, T cells, and other } \\
\text { immune cells }\end{array}$ \\
\hline CXCL9/10/11 & $\begin{array}{l}\text { Monocytes, alveolar epithelial cells, bronchial epithelial } \\
\text { cells, dendritic cells, B cells }\end{array}$ & Recruitment of a variety of immune cells \\
\hline CXCL13 & Dendritic cells, pulmonary fibroblasts & $\begin{array}{l}\text { B cells recruitments, granuloma associated follicular } \\
\text { structure formation }\end{array}$ \\
\hline CCL19/21 & Stromal cells of secondary lymphoid organs & $\begin{array}{l}\text { T cells recruitment, dendritic cells migration from lung to } \\
\text { draining mediastinal lymph nodes }\end{array}$ \\
\hline
\end{tabular}

formation and containment of infection within granuloma, we found that a complex network of cytokines and chemokines plays a directing role in these cellular activities [37]. Table 1 summarizes the role of major effector molecules in granuloma formation and its maintenance.

\section{Immune evasion by Mycobacterium tuberculosis}

During the host-pathogen interaction, the host tries to kill the invading pathogen on the one hand, while on the other hand, the pathogen develops survival strategies to evade host defenses and as a result of this multidirectional interaction, many different kinds of effector molecules including pro-inflammatory cytokines IFN- $\gamma$ and TNF- $\alpha$ are produced [38]. A wealth of experimental evidences generated from animal models suggests that both IFN- $\gamma$ and TNF- $\alpha$ play a pivotal role in eliciting the anti-mycobacterial response against MTB, via inducible nitric oxide synthase (iNOS)-dependent mechanism. After activation of macrophages by these cytokines, a considerable amount of toxic reactive nitrogen intermediates (RNIs) and reactive oxygen intermediates (ROIs) are produced, which ultimately act against intracellular MTB residing 
in macrophages and likely to kill the pathogen [39, 40]. To counteract, MTB induces the production of IL-10 for suppressing the activity of iNOS via MyD88-dependent mechanism [41]. Transforming growth factor $\beta 1$ (TGF- $\beta 1$ ) has also been reported to help the intracellular MTB in evading the host killing response by impairing the function of macrophages and T cells [42].

A number of mycobacterial proteins have been implicated in evading the host immune response [43-45]. Of these, small heat shock protein 16.3 (sHSP16.3) is a crucial protein of MTB that helps the bacteria not only in maintaining its long-term persistence [46], but also in continuing its growth in macrophages [47]. sHSP16.3 is also a good target for drug [48] and vaccine development $[49,50]$. Recently, it was demonstrated that when MTB-infected macrophages are exposed to recombinant IFN- $\gamma$, the gene $h s p X$ encoding sHSP16.3 is up-regulated, whereas treatment of infected macrophage with recombinant IL-10 results in down-regulation of $h s p X$. [51]. However, the mechanism facilitating this modulation is yet to be explored.

\section{Conclusions}

Although the host immune machinery against MTB is well explored in animal models, its various rate limiting steps are still not well understood in human cases. Future effort may be focused to study the underlying mechanism of formation of granuloma and its maintenance as well as to unravel the inside story of MTB-mediated evasion of host antimicrobial actions in human tuberculosis. The elucidation of role of small heat shock protein 16.3 (sHSP16.3) in conferring protection to MTB from hostile environment of macrophages may also give a new insight.

\section{The author declares no conflict of interest.}

\section{References}

1. Lehmann KB, Neumann RO (1896): Atlas und grundriss der bakteriologie und lehrbuch der speciellen bakteriologischen diagnostik. Vol 1. München.

2. World Health Organization (2017): Global tuberculosis report 2017. WHO, Geneva.

3. Narasimhan P, Wood J, MacIntyre CR, Mathai D (2013): Risk factors for tuberculosis. Pulm Med 2013: 828939.

4. Millet JP, Moreno A, Fina L, et al. (2013): Factors that influence current tuberculosis epidemiology. Eur Spine J 22: S539-S548.

5. Perlman DC, Salomon N, Perkins MP, et al. (1995): Tuberculosis in drug users. Clin Infect Dis 21: 1253-1264.

6. Puri AS, Desai D, Sood A, Sachdeva S (2017): Infliximab-induced tuberculosis in patients with UC: Experience from India-a country with high prevalence of tuberculosis. J Gastroenterol Hepatol 32: 1191-1194.
7. Naudžiūnas A, Juškaitė R, Žiaugrytė I, et al. (2012): Tuberculosis complications after BCG treatment for urinary bladder cancer. Medicina (Kaunas) 48: 563-565.

8. Pieters J (2001): Entry and survival of pathogenic mycobacteria in macrophages. Microbes Infect 3: 249-255.

9. Flynn JL, Chan J (2001): Immunology of tuberculosis. Annu Rev Immunol 19: 93-129.

10. Nardell E (1993): Pathogenesis of tuberculosis. In: Lung biology in health and disease. Reichman LB, Hirschfield E (eds.). Marcel Dekker Inc, New York: 103-123.

11. Weiss G, Schaible UE (2015): Macrophage defense mechanisms against intracellular bacteria. Immunol Rev 264: 182203.

12. Desjardins M (1995): Biogenesis of phagolysosomes: the 'kiss and run' hypothesis. Trends Cell Biol 5: 183-186.

13. Fratti RA, Vergne I, Chua J, et al. (2000): Regulators of membrane trafficking and Mycobacterium tuberculosis phagosome maturation block. Electrophoresis 21: 3378-3385.

14. Sturgill-Koszycki S, Schlesinger PH, Chakraborty P, et al. (1994): Lack of acidification in Mycobacterium phagosomes produced by exclusion of the vesicular proton-ATPase. Science 263: 678-681.

15. Waters MG, Pfeffer SR (1999): Membrane tethering in intracellular transport. Curr Opin Cell Biol 11: 453-459.

16. Jahn R, Sudhof TC (1999): Membrane fusion and exocytosis. Annu Rev Biochem 68: 863-911.

17. Zerial M, McBride H (2001): Rab proteins as membrane organizers. Nat Rev Mol Cell Biol 2: 107-117.

18. Vieira OV, Botelho RJ, Grinstein S (2002): Phagosome maturation: aging gracefully. Biochem J 366: 689-704.

19. Ferrari G, Langen H, Naito M, Pieters JA (1999): Coat protein on phagosomes involved in the intracellular survival of mycobacteria. Cell 97: 435-447.

20. Saunders BM, Cooper AM (2000): Restraining mycobacteria: role of granulomas in mycobacterial infections. Immunol Cell Biol 78: 334-341.

21. Springer TA (1994): Traffic signals for lymphocyte recirculation and leukocyte emigration: the multistep paradigm. Cell 76: 301-314.

22. Schluger NW, Rom WN (1997): Early responses to infection-chemokines as a mediators of inflammation. Curr Opin Immunol 9: 504-508.

23. Orme IM (1998): The immunopathogenesis of tuberculosis: a new working hypothesis. Trends Microbiol 6: 94-97.

24. Orme IM, Cooper AM (1999): Cytokine chemokine cascades in immunity to tuberculosis. Immunol Today 20: 307-312.

25. Lima VM, Bonato VL, Lima KM, et al. (2001): Role of trehalose dimycolate in recruitment of cells and modulation of production of cytokines and NO in tuberculosis. Infect Immun 69: 5305-5312.

26. Dannenberg AM Jr, Ando M, Shima K (1972): Macrophage accumulation, division, maturation, and digestive and microbicidal capacities in tuberculous lesions. III. The turnover of macrophages and its relation to their activation and antimicrobial immunity in primary BCG lesions and those of reinfection. J Immunol 109: 1109-1121.

27. Dannenberg AM Jr (1989): Immune mechanisms in the pathogenesis of pulmonary tuberculosis. Rev Infect Dis 11: S369-S378.

28. Adams D (1974): The structure of mononuclear phagocytes differentiating in vivo. I. Sequential fine and histologic studies of the effect of bacillus Calmette-Guerin (BCG). Am J Pathol 76: $17-48$. 
29. Ulrichs T, Kaufmann SH (2006): New insights into the function of granulomas in human tuberculosis. J Pathol 208: 261269.

30. Flynn JL, Chan J (2004): Animal models of tuberculosis. In: Tuberculosis. Rom WN, Garay SM (eds.). Lippincott Williams \& Wilkins. Philadelphia: 237-250.

31. Scriba TJ, Coussens AK, Fletcher HA (2017): Human immunology of tuberculosis. Microbiol Spectr 5: TBTB2-00162016.

32. D'Souza CD, Cooper AM, Frank AA, et al. (2000): A novel nonclassic beta2-microglobulin-restricted mechanism influencing early lymphocyte accumulation and subsequent resistance to tuberculosis in the lung. Am J Respir Cell Mol Biol 23: 188-193.

33. Ramoner R, Rieser C, Herold M, et al. (1998): Activation of human dendritic cells by Bacillus Calmette-Guerin. J Urol 159: 1488-1492.

34. Orme IM (1987): The kinetics of emergence and loss of mediator $\mathrm{T}$ lymphocytes acquired in response to infection with Mycobacterium tuberculosis. J Immunol 138: 293-298.

35. Feng CG, Bean AG, Hooi H, et al. (1999): Increase in gamma interferon-secreting CD8 (+), as well as CD4 (+), T cells in lungs following aerosol infection with Mycobacterium tuberculosis. Infect Immun 67: 3242-3247.

36. Johnson CM, Cooper AM, Frank AA, Orme IM (1998): Adequate expression of protective immunity in the absence of granuloma formation in Mycobacterium tuberculosis-infected mice with a disruption in the intracellular adhesion molecule 1 gene. Infect Immun 66: 1666-1670.

37. Domingo-Gonzalez R, Prince O, Cooper A, Khader SA (2016): Cytokines and chemokines in Mycobacterium tuberculosis infection. Microbiol Spectr 4: TBTB2-0018-2016.

38. Flynn JL, Chan J (2003): Immune evasion by Mycobacterium tuberculosis: living with the enemy. Curr Opin Immunol 15: 450-455.

39. Ehrt S, Schnappinger D (2009): Mycobacterial survival strategies in the phagosome: defence against host stresses. Cell Microbiol 11: 1170-1178.

40. Guirado E, Schlesinger LS, Kaplan G (2013): Macrophages in tuberculosis: friend or foe. Semin Immunopathol 35: 563-583.

41. Shi S, Nathan C, Schnappinger D, et al. (2003): MyD88 primes macrophages for full-scale activation by interferon-gamma yet mediates few responses to Mycobacterium tuberculosis. J Exp Med 198: 987-997.

42. Aung H, Wu M, Johnson JL (2005): Bioactivation of latent transforming growth factor $\beta 1$ by Mycobacterium tuberculosis in human mononuclear phagocytes. Scand J Immunol 61: 558-565.

43. Sampson SL (2011): Mycobacterial PE/PPE proteins at the host-pathogen interface. Clin Develop Immunol 2011: 497203.

44. Gengenbacher M, Kaufmann SH (2012): Mycobacterium tuberculosis: success through dormancy. FEMS Microbiol Rev 36: 514-532.

45. Singh P, Rao RN, Reddy JR, et al. (2016): PE11, a PE/PPE family protein of Mycobacterium tuberculosis is involved in cell wall remodeling and virulence. Sci Rep 6: 21624.

46. Yuan Y, Crane DD, Barry CE $3^{\text {rd }}$ (1996): Stationary phaseassociated protein expression in Mycobacterium tuberculosis: function of the mycobacterial alpha-crystallin homolog. J Bacteriol 178: 4484- 4492.

47. Yuan Y, Crane DD, Simpson RM, et al. (1998): The 16-kDa alpha-crystallin (Acr) protein of Mycobacterium tuberculosis is required for growth in macrophages. Proc Natl Acad Sci USA 95: 9578-9583.

48. Jee B, Kumar S, Yadav R, et al. (2018): Ursolic acid and carvacrol may be potential inhibitors of dormancy protein small heat shock protein16.3 of Mycobacterium tuberculosis. J Biomol Struct Dyn 36: 3434-3443.

49. da Costa AC, Costa-Júnior Ade O, de Oliveira FM, et al. (2014): A new recombinant BCG vaccine induces specific Th17 and Th1 effector cells with higher protective efficacy against tuberculosis. PLoS One 9: e112848.

50. Wieczorek AE, Troudt JL, Knabenbauer P, et al. (2014): $\mathrm{HspX}$ vaccination and role in virulence in the guinea pig model of tuberculosis. Pathog Dis 71: 315-325.

51. Jee B, Sharma P, Katoch K, et al. (2017): IL-10 down-regulates the expression of survival associated gene $h s p X$ of Mycobacterium tuberculosis in murine macrophage. Braz J Infect Dis 21: 386-390. 